\title{
Understanding Barriers to Compliance to Food Safety Standards in the Catering Establishments Using a Qualitative Research Method: Focus Group Discussion \\ Veena Kumari ${ }^{1}$, Deeksha Kapur ${ }^{2}$
}

${ }^{1}$ Research Scholar, School of Continuing Education, Indira Gandhi National Open University, New Delhi, India 2Professor, School of Continuing Education, Indira Gandhi National Open University, New Delhi, India

\section{ABSTRACT}

Background: Now a days trend of eating out has increased so also the responsibility of catering establishments to serve safe and wholesome food to its consumers. In India food safety is currently considered to be an important issue for all the stakeholders in the area of food production. This study was conducted to understand food handlers perceptions, opinions, beliefs to compliance to food safety standards in the catering establishments in Delhi.

Methods: Nine focus group sessions were conducted with catering establishments owners ,administrators and food handlers ,from March to September 2017. One FGD was conducted in each District of Delhi , India ,with 6 to 8 participants in each group to identify their barriers, opinions and belief systems to compliances to food safety operations in the catering establishments. Focus group were conducted using a questionnaire having check points for discussions with participants which included questions related to personal hygiene and their understanding to FSSAI norms and facilities. Hygiene game (word hunt game) was also developed and was played with participants to build rapport before focus group sessions.

Results: A total of 64 food handlers including catering establishments owners and administrators participated in focus group discussions. Affinity diagram had been used to compile data and six themes emerged out of interactive sessions which reflected the participant's perception, barriers, opinions and belief systems to compliance to food safety norms and standards in the catering establishments. Though the participants realized the importance of implementing food safety standard principles but being busy with their daily routine jobs ,they had never tried to gather relevant information. They had also addressed other major barriers like attachment with their old deep rooted practices and pressure of delivering orders on time, less space and poor infrastructure facilities.

Conclusions: The perceived barriers gathered from these focus groups sessions can provide a base to sensitize the catering establishment administrators/owners and workers towards the specific food safety needs.

Keywords : Focus Group Discussion, Food Safety, Perceptions, Opinions, Belief, FSSAI

\section{INTRODUCTION}

India has a fairly sophisticated F\&B market, which is growing steadily. We have enough restaurants in
Delhi, Mumbai, Bangalore and Chennai, but there have been allegation in past that all restaurants are not appropriately following the food safety guidelines in the country. During last three-five years, restaurants 
those were serving high-quality food have neglected the food safety guidelines. A food safety audit of kitchens at India's 12 top central institutions of higher education by the Food Safety and Standards Authority of India (FSSAI) has found that most were not following food safety standards. The report revealed that most of the institutions audited did not adhere to basic hygiene and infrastructure of kitchens was poor. Only the Indian Institute of Management, Ahmedabad (IIM-A) and Indian Institute of Technology, Roorkee (IIT-Roorkee) were in a better position when compared to the others ( Sushma Meenakshi,2018).

Food can be a potential source of infection and disease, right from the point of preparation from to the point of consumption. It is more likely in Food Service Establishment where mass food is prepared (Adams M, Motarjemi Y,1999). Epidemiological and surveillance data suggest that faulty practices and poor infrastructure facilities in food plants and food service establishments play a crucial role in the causal chain of food borne diseases. It is easy to spread bacteria to food without realizing. As these bacteria are invisible and can make people ill. Most of the food borne diseases may be self-limiting but some can be very serious and even lead to death. The scientific investigations/reports on outbreak of foodborne diseases in India for the past 29 (1980-2009) years indicated that a total of 37 outbreaks involving 3,485 persons have been affected due to food poisoning [Sudershan et al, 2012].The Union Health Ministry's Integrated Disease Surveillance Programme (IDSP) has indicated that food poisoning is one of the commonest outbreaks reported in 2017. This is apart from acute diarrhoeal disease (ADD).According to the data (Figure 1 below), 312 of the 1,649 outbreaks reported till the third week of December 2017 were due to ADD and 242 were due to food poisoning. The IDSP has interpreted that the incidence of ADD and food poisoning is high in places where food is cooked in bulk, such as canteens, hostels and wedding venues ( Yasmeen Afhsan, 2018).

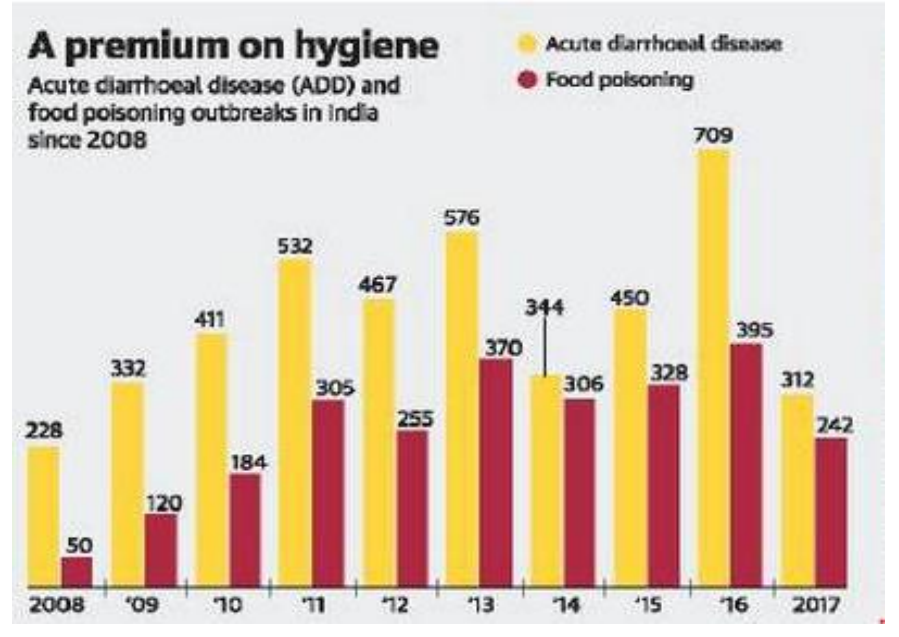

Figure 1 : Acute Diarrheal Disease (ADD) and Food Poisoning Outbreaks in India since 2008

The health authorities in India are also getting active towards legalizing the food safety and hygiene monitoring system in food service establishments. The Food Safety and Standards Act, 2006 is the primary law for the regulation of food products and formulation and enforcement of food safety standards in the country. The Food Safety and Standards Act received the assent of the President on 23rd August, 2006 and came into effect on 5th August, 2011. The Act is intended as an "umbrella law" for food safety by consolidating older laws, rules and regulations like Prevention of Food Adulteration Act, 1954 Fruit Products Order, 1955, eat Food Products Order, 1973, Vegetable Oil Products (Control) Order, 1947, Edible Oils Packaging (Regulation) Order 1988, Solvent Extracted Oil, De-Oiled (FSS Act ,2006 ).

\section{Food Safety and Hygiene Requirements as per Schedule 4 of FSS Regulations 2011}

To provide assurance of food safety, Food businesses must implement an effective Food Safety Management System (FSMS) based on Hazard Analysis and Critical Control Point (HACCP) and suitable pre- requisite programmes by actively controlling hazards 
throughout the food chain starting from food production till final consumption. As per the condition of license under FSS (Licensing \& Registration of Food Businesses) Regulations 2011, every food business operator (FBO) applying for licensing must have a documented FSMS plan and comply with schedule 4 of this regulation. Schedule 4 introduces the concept of FSMS based on implementation of Good Manufacturing Practices (GMP) and Good Hygiene Practices (GHP) by food businesses and is divided into five parts as under ( FSS Regultaion, 2011).

Table 1 : Schedule 4 General hygienic and sanitary practices to be be followed by all kinds of food business operators

\begin{tabular}{|l|l|}
\hline Schedule 4 & \multicolumn{1}{|c|}{ General Requirements } \\
\hline Part 1 & $\begin{array}{l}\text { General hygienic and sanitary } \\
\text { practices to be followed by food } \\
\text { business operators applying for } \\
\text { registration - Petty food operators } \\
\text { and Street food vendor }\end{array}$ \\
\hline Part 2 & $\begin{array}{l}\text { General hygienic and sanitary } \\
\text { practices to be followed by food } \\
\text { business operators applying for } \\
\text { license manufacturing/ processing/ } \\
\text { packaging/storage/distribution }\end{array}$ \\
\hline Part 3 & $\begin{array}{l}\text { General hygienic and sanitary } \\
\text { practices to be followed by food } \\
\text { business operators applying for } \\
\text { license for milk and milk products }\end{array}$ \\
\hline Part 4 & $\begin{array}{l}\text { General hygienic and sanitary } \\
\text { practices to be followed by food } \\
\text { business operators applying for } \\
\text { license for slaughter house and meat } \\
\text { processing }\end{array}$ \\
\hline $\begin{array}{l}\text { General hygienic and sanitary } \\
\text { practices to be followed by food } \\
\text { business operators applying for } \\
\text { license catering }\end{array}$ \\
\hline Part 5
\end{tabular}

Source : Food Safety And Standards (Licensing And Registration Of Food Businesses), Regulations 2011.

Therefore, food safety is currently considered to be an important issue not only for all the stakeholders in the area of food production but as well as for the government also to establish new legislation regarding food safety.

\section{RATIONALE OF THE STUDY}

Research and many studies have indicated that restaurants don't follow the Food Safety Standard Norms either they are unaware of the norms or they neglect it or they follow faulty practices. With volume processing and preparation of food, effect of contamination is accentuated which could be due to :Human errors (as cross-contamination, time and temperature abuse, and poor personal hygiene) and Non human errors ( environmental violations, such as poor maintenance and lack of facilities).Thus, Food safety practices in the hospitality industry has become an international requirement and vital for all those involved in food handling and preparation. Also, One Nation One Food Law ( FSSAI) approach has shifted from a reactive to a preventive approach. With this view, the present research paper specifically reviewed the perceived barriers, opinions and belief systems to compliance to food safety operating procedures among food handlers in selected catering establishments.

\section{Purpose of the Study}

The purpose of the study was to assess the readiness and preparedness of the Selected Catering Establishments in Implementing Food Safety Standards and Procedures and to determine the perceived barriers to compliance to food safety operating procedures among food handlers/administrators/owners..

\section{Assumptions of the Study}


For the purpose of this study, the following assumptions had been made:

1. Catering Establishments applied FSSAI Compliances and the required control measures.

2. Catering establishments owners/administrators and food handlers were willing and free to provide honest and unbiased responses .

\section{Significance of the Study}

The results will be of great importance to policy makers and the Food Business Operators (FBO) as well as the researchers. The perceived barriers gathered from these focus groups sessions can serve as a base to sensitize the catering establishment administrators/owners and workers towards the specific food safety needs .First, the Food Business Operators will get to know the types of barriers being existing in their system. They can take corrective and preventive actions to promote safe food handling practices and thus, assurance of serving safe and wholesome food. Secondly the policy-makers will get a deeper insight towards existing barriers which influence the slow implementation of FSSAI standards in the catering establishments. Food Safety Regulatory Authorities can use the information to establish or reframe policies for the easy implementation of FSSAI system which can motivate the stakeholders in producing wholesome food . To the researchers, it will provide a basis for further research aimed at isolating the causal relationship between the various variables used in the study.

\section{Scope and Limitations of this Study}

\section{Scope of the Study}

The research would point out the perceived barriers existing both at employee and management level to compliance to food safety operating procedures in the catering establishments. It can provide a base to sensitize the catering establishment administrators/owners and workers towards the specific food safety needs.

\section{Limitations}

1. The generalizations of this study can't be made as the intent of a focus group qualitative technique is to understand, and not infer.

2. The responses obtained from volunteered participants may or may not represent the larger population of food handlers working in the catering establishments. Since, the study was limited to urban vegetarian catering establishments and the perceived barriers and opinions existing may not wholly be similar to urban non vegetarian catering establishments, street food vendors, rural catering establishments, school/college/ hospital canteen and road side dhabas etc.

3. Many of the catering establishments were not willing to participate in the study .References were used to get an access to the catering establishment which cannot be considered as a proper representation of the population .Thus, samples selected from the city cannot be considered as a proper representation of the population of the country.

4. Despite warming up session and probing efforts by the researcher, it is possible that some participants may not have expressed and addressed their view points. There were no "true" or "false" statements and the participants were encouraged to give their personal view points towards the questionnaire checkpoints based on their degree of agreement or disagreement .

\section{Conceptual Framework}


This present study had identified both dependent and independent variables (figure2 below) which would have positive or negative effect on food safety in catering establishment and the conceptual framework was based on the schedule IV of FSS Act , 2006 guidelines.

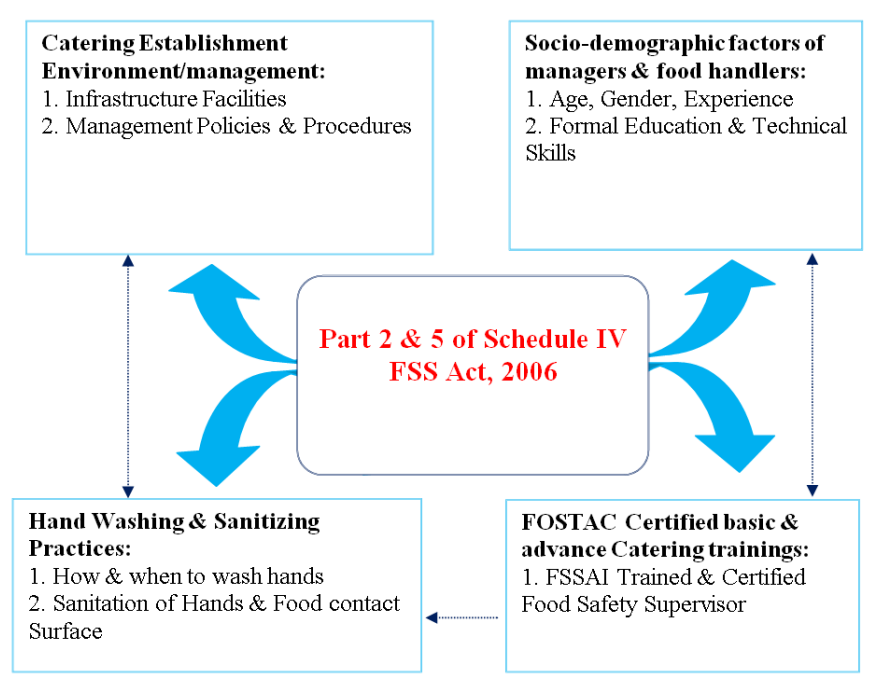

Figure 2 : Conceptual Framework based on Schedule 4 , FSS Act, 2006

\section{REVIEW OF LITERATURE}

Now a days there is a tremendous boom in catering industry, eating out is not uncommon and today people venture out of their homes more often to savor delicacies. This poses extra responsibilities on the food businesses to ensure safe and wholesome food to its consumers. It is estimated that about 23 to $30 \mathrm{Cr}$ people are eating either a meal or a snack from some outside kitchen daily ( FSSAI,2018, Guidance Document Catering Sector). Indians spend a high proportion of their incomes on food and groceries, compared to consumers in other countries, and food consumption and demand are expected to grow considerably over the next few years. In value terms, the Indian food market is the 6th largest in the world, with $70 \%$ of sales coming from the retail sector. By 2025, Indians are expected to eat processed food valued at Rs 72 lakh crore annually, while the revenues of the country's processed food industry have been forecast to touch Rs 60 lakh crore. The restaurant industry is expected to contribute about 2.1 percent to the total GDP of India by 2021 ( Sharma Charu, 2017).

\section{Factors Affecting Food Safety in Restaurants}

There are many factors involved in food safety but the potential threat were classified into three categories: food hygiene , personal hygiene of food handlers and kitchen sanitation.

\section{Food Hygiene}

Many factors serve to undermine food hygiene. The hygienic quality of the foods is negatively influenced by purchasing low-quality or stale foods, storing food in inappropriate conditions, cooking large amounts of food, more than is necessary, and letting it sit in inappropriate environments, storing raw and cooked foods together and preparing, cooking and storing food using incorrect methods ( Yigit, Duan,1997).Microorganisms can reproduce very rapidly at room temperature. Temperatures below $5^{\circ} \mathrm{C}$ and above $60^{\circ} \mathrm{C}$ cause the reproduction of microorganisms to slow down or stop.

\section{Personal Hygiene of Food Handlers}

The food processing staff should include healthy individuals who do not have any diseases, and they should undergo regular medical check-ups. The hygiene practices that should be performed by food processing workers include precise adherence to personal hygiene regulations and wearing of special, protective attire (Codex Alimentarius,2009). Reports have shown that the lack of personal hygiene among workers at food processing sites was among one of the practices that contributed to food borne diseases and that proper hand washing was the most commonly neglected practice. The practice of improper hand washing may be an important factor in the spreading of foodborne diseases by cross-contamination ( Cogan , 
Slader, Bloom Weld and. Humphrey,2002 and Collins, 2001). It was also reported that food processing and food service workers were the asymptomatic carriers of the pathogens which caused food poisoning, due to their failure to wash their hands properly after using the restroom (Temelli, C.M.K. , Anar, 2007).

\section{Kitchen Hygiene and Sanitation}

Another important issue in the provision of food safety is kitchen hygiene and sanitation. In order to minimize the risk of foodborne illnesses in the production and processing of foods, it is necessary to minimize the risk of contamination in the placement, arrangement and decking of kitchen utensils, to set up the area so that it is equipped to perform maintenance, repair, cleaning and disinfection and to ensure that surfaces and materials in the kitchen are anti-toxic, that the kitchen has control mechanisms for temperature and humidity (Codex Alimentarius,2009). Drainages should be easy to clean and prevent pests such as rodents from entering and waste liquids from re-entering back into the kitchen environment. Ventilation systems should be capable of eliminating smoke, odors, soot and preventing dust, dirt and pests from entries (Anon, 2011).

\section{Equipment Hygiene}

Equipment that comes into regular contact with foods should be made of material able to be cleaned and disinfected, resistant to corrosion and non-toxic. Calibration checks of the equipment and tools should be made regularly, and these checks should be recorded (Anon, 2011).

\section{METHODOLOGY}

The study was a descriptive cross sectional study to understand the perceived barriers to compliance to food safety operations in selected catering establishments. The qualitative research technique
"Focus Group Discussion" was used to collect data from food handlers/catering establishment owners and administrator in their natural setting. Research following a qualitative approach is exploratory, helps in gaining new insight and seeks to explain 'how' and 'why' a particular phenomenon, or behavior operates. (McLeod, S. A.,2017).

\section{Study Area}

The study was conducted in selected catering establishments located in Delhi, the Capital of India which is the second most populous city in India after Mumbai. It is a place of amalgamation of several cuisine styles for people who came from different parts of the country and settled in Delhi. Delhi is known for two things rich culture and mouth watering food and the Capital is called "DelhiBelly"(Julie Raj,2012).Delhi has been virtually divided into nine districts as North, South, East, West and Central, North west, North East, South West and New Delhi District. The Catering Establishment for the study were selected from all the nine districts of Delhi using snow ball non probability sampling technique.

\section{Data Collection Procedure}

Between March to September 2017, nine focus group sessions were conducted in both English and Hindi language which lasted for 45-50 minutes on an average and was undertaken within the catering establishment environments. In total 6 to 8 participants were there in each group. Krueger \& Casey (2000) also suggested between six and eight participants, as smaller groups show greater potential. However, the number generally suggested as being manageable is between six and ten participants; large enough to gain a variety of perspectives and small enough not to become disorderly or fragmented. Snow ball sampling technique was used to select catering establishment from all the nine districts of Delhi. Snowball sampling method is based on referrals from 
initial subjects to generate additional subjects via chain referral (Dudovskiy John.2018).The subjects within focus groups were homogenized with respect to their social roles and categories. This homogeneity allowed each participant's interaction and discussion of their opinions together with the views and perspectives of the other participants .

Focus group were conducted using a questionnaire having check points for discussions .Before initiating the focus group session a Hygiene game ( Word Hunt Game ) had also been played with food handlers in order to develop a rapport with them and making them at ease during FGD sessions keeping in mind the purpose of the study to identify the most obvious barriers and their belief system while implementing food safety standards in the establishment and preventing the workers from always practicing safe food handling practices.

\section{Inclusion Criteria of Catering Establishment:}

Establishment Category: Catering Establishment involved in processing ,handling, storing, serving and packing of food.

\section{$\checkmark$ Business Ownership: Private Limited /} Proprietorship/Partnership

$\checkmark$ Type : Family Restaurant

$\checkmark$ License Category State/Central

$\checkmark$ Restaurant size: Medium with seating capacity of 40 -100 customer

$\checkmark$ Service: Self Service

$\checkmark$ Cuisines : Must serve North Indian and Traditional sweets

$\checkmark$ Food Specializations: Pure Vegetarian

$\checkmark$ Average Coupon Size: Rs 500 for two persons plus minus 10\% ( Non festival season)

$\checkmark$ Sale : More than Rupees12 lac per annum

\section{Exclusion Criteria for Catering Establishments}

$\checkmark$ Catering establishment who didn't give permission was not selected

$\checkmark$ Catering establishments not serving North Indian Food was not included in the study.

$\checkmark$ Catering establishment had bars and fine dining service was not included in the study.

$\checkmark$ Catering establishment not serving pure vegetarian food was not selected for the study.

$\checkmark$ Catering establishment not carrying a license at the time of study was not included in the study.

\section{Pilot Study}

The Focus group checkpoints were pilot tested on a simple random sample in non participating catering establishment before carrying out the formal phase of qualitative research. Pretesting instruments helped to ascertain that the instrument for collecting data was free from any flaws, errors, pitfalls and mistakes that would have come into notice while collecting the main data, if the pretesting of the instrument had not been done. After pilot study, the instrument was revised and refined to enhance the reliability and validity of the final tools.

\section{Ethical Considerations}

The approval to conduct research was obtained from the School of Continuing Education (SOCE) ,IGNOU, Maidan Garhi, New Delhi,India. Before collecting data the aim and objectives of the study were fully explained to the owners of catering establishment , managers/supervisors and food handlers .The consent form was given to each participant who agreed to take part in the study. The signed consent was taken from the subjects. Also, the subjects had the right to withdraw their names anytime from the study or they could refuse to answer any question. Participation in the study was purely on voluntary basis. Participants identification was also kept confidential.

\section{RESULTS}


The results related to focus group discussions were sorted and organized with an aim to get a deeper insight of the catering establishment's owners ,administrators and food handler's perception, opinions and belief system while implementing food safety standards in the establishment and preventing them from always practicing safe food handling practices.

\section{Participants}

A total of 64 food handlers including owners and administrators participated in focus group sessions. Only three participants were female and rest 61 were males. Participants total work experience ranged from one year to 25 years with a mean to 14 years. The number of participants in each group ranged from 6 to 8 individuals and each session was lasted for 45 to 50 minutes on an average and was undertaken within the catering establishment environment. Nine focus group sessions were conducted in both English and Hindi language whereas focus group discussion for catering establishments owners were conducted separately so that they can freely express their view points.Similarly, food handlers groups were segregated from their managers so that they could address their issues without any fear .

\section{Belief System ,Opinions and Perceived Barriers of Employees and Management to Compliance to Food Safety Standards.}

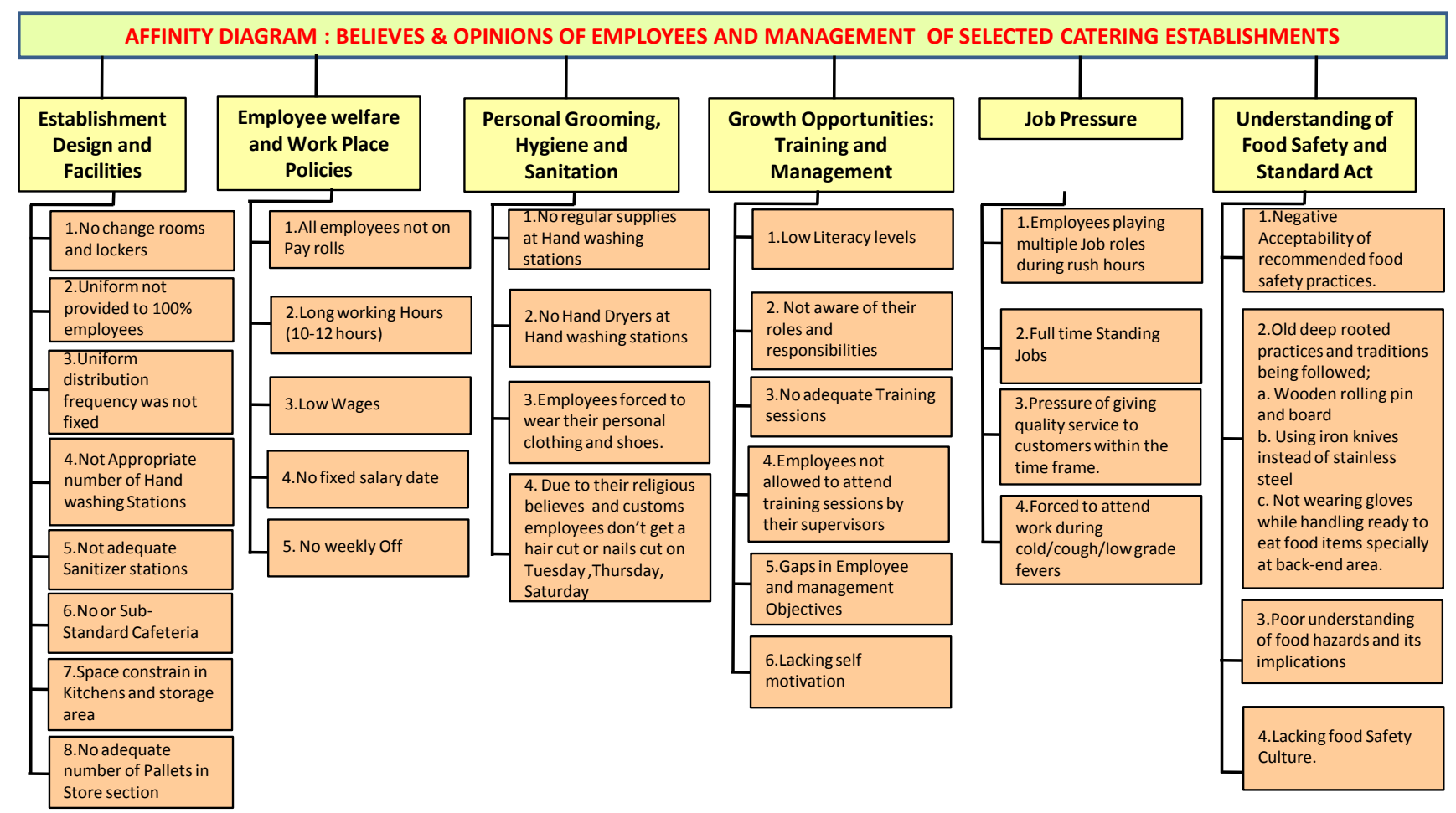

Figure 3 : Affinity Diagram: Beliefs and Opinions of Employees and Management.

The Focus group session was started with warming up session "Word Hunt Game". This hygiene game had motivated the participants and they opened up. The participants actively answered the questions and expressed their belief system, opinions and perceived barriers which prevented them to practice safe food handling practices in their work settings. The following six themes emerged from the discussion: Establishment design and facilities, Employee welfare and work place policies, Personal grooming, hygiene 
and sanitation, Growth opportunities, Job Pressure, Understanding of Food safety and Standard Act, 2006. All the Identified barriers were grouped into six categories with suitable thematic headings. Thirty one challenges were grouped into six themes as shown in figure 3. An affinity diagram had been used as an analytical tool for compiling and sorting collected data by brainstorming. The affinity diagram is a visual technique to organize ideas and information. Affinity diagramming is an inductive technique which starts from the bottom with fragments of ideas, behaviors, and observations and end up with "top" groups and relationships. Its main benefit is in taking what may seem like disconnected information and finding potentially hidden associations and patterns to reveal latent themes using a low-tech and quick approach. The method is reported to have been developed by Jiro Kawakita who developed it as one of his seven quality tools in the 1960s and so is sometimes referred to as the K-J method (Sauro Jeff,2016).

\section{Opinions of the participants on Establishment Design and Facilities}

When the issue of infrastructure and establishment design was discussed majority of the participants underlined poor infrastructure facilities and less space as responsible factors for not allowing them to follow food safety culture in the catering establishment. Few respondents highlighted that firstly the commitment from management was required that can build an organizational culture with safe working conditions which not only motivates employees but also empower them to meet their food safety responsibilities. Few participants also underlined the fact that due to smaller food storage area "which they call it as central stores..." they were forced to keep the food items beyond facility capacity and also on floor as sufficient number of pallets and racks had not been provided and due to smaller kitchen designs compared to menu items there were not able to follow all the set standards of FSSAI specific to production and to separate 'clean' from 'dirty' areas of operation which may poses a higher risk of cross contamination. Most of the participants were found to be aware about serious repercussions of not adopting food safety practices and were open to adopt all food safety standards if they were provided with all the desired and standard facilities as per the norm. Almost all the participants highlighted that any non compliance not only at the management level but at their level also would set a bad name and fame for the entire organization Majority of the participants were found to be aware about the importance of uniform and importance of washing and sanitizing hands at work place. They had no inhibitions in wearing uniform and washing hands but the adequate provisions from the management had not been made in the premises. Some of the important inadequate infrastructure facilities identified and discussed by the participants were uniform, shoes, lockers, changing room, staff cafeteria, inadequate number of hand washing stations and employees toilets .

\section{Perceptions of the Participants about Employee Welfare and Workplace Policies}

On being asked about these workplace policies almost all the participants mentioned the pain point of long shift duty of 10-12 hours with no weekly offs and no fixed salary dates specially for contractual employees. They were getting only two offs in a month and the food handlers were not even taking their entitled offs .When asked why they worked during off-time, they gave the reason that they were getting three meals (breakfast, lunch and dinner) with evening snacks and tea according to the staff welfare policy and most food handlers had shifted from their native places in their workplace cities and they had no arrangement for cooking food. Their wages were low and they had to send their earnings to their families living in the villages and in the end they did not have any money for their personal expenditure. Therefore, during the holidays, they used to work, otherwise 
they had to starve all day. They also discussed that due to long working hours they didn't get time to wash clothes and follow grooming standards like shaving etc whereas they were expected to maintain a very high standard of personal appearance and uniform regulations. Very few also stated that long shift duty was a normal cultural practice of this catering industry. Majority of the respondents in the discussion also opposed of long working hours and looked for equal status to supervisory staff by highlighting various measures such as break duty, provision of one weekly off with sick leave .

\section{Opinions of the participants regarding Job Pressure}

Majority of the participants highlighted that management always expected ownership, precision , accuracy, ethics , courtesy, quality, efficiency and commitment from them. According to them in service industry each task needed to be completed in time with precision and efficiency by adhering to laid down food safety standard principles at all the points of time during work. Most of the participants also discussed the long term negative consequences of always being on toes and under continuous job stress which caused mental uneasiness and disturbance. Many of them also stated that they had also felt a change in their behavior and they became volatile not only with their seniors and co- workers but at times with customers also. Various reasons of stress mentioned by them were inadequate infrastructure and facilities, poor ventilation system, low wages compared to job roles and responsibilities they handle, standing jobs, lots of rules and regulations and lack of career growth opportunity. A good number of participants also stated that they were being called from their residence during acute illnesses due to the shortage of manpower and were forced to work either part time or only during rush hours. This was a common practice specially during festivals. They also underlined that such practices had affected their productivity and efficiency.

\section{Beliefs and Opinions of the participants on Personal Grooming , Hygiene and Sanitation}

When asked to describe their daily personal grooming, hygiene and sanitation practices at work and almost all of them stated the following common procedures and practices: daily shower, brushed teeth ,maintaining short and trimmed hair ,beard and nails, washing and sanitizing hands with soap and water frequently, wearing clean uniform ,polished shoes, complete covering of hair by wearing a cap in food production and service area, wearing no jwellery like bracelets, necklace, threads on wrists and watches ,covering all wounds or cuts on hands with bandages, wearing gloves while handling ready to eat food items, no eating ,smoking or chewing tobacco at work station and cleaning and sanitation of work surfaces and utensils. Though the food handlers were aware of all workplace policies but during discussion it was observed food handlers were not well groomed Their beard was visible, hair not trimmed, nails were dirty and not cut short, tobacco stains on teeth were visible and on being asked about these poor grooming and hygiene practices they stated that due to their religious beliefs and customs they didn't get their hair and nails cut on Tuesday, Thursday and Saturday. Almost all participants in the discussion were found to be aware of about the negative effects of eating tobacco on health but they disclosed that they were habitual of the substance abuse but they avoided eating tobacco at work stations. When asked to describe how often they washed hands and what materials were used to wash their hands at work. Participants replied with frustration that number of hand washing stations were inadequate and cleaning consumables like liquid soap and single use paper towels for drying hands were not replenished on daily basis. Though they frequently wash hands but with 
plain water and sanitize their hands after that. They also stated that sometimes during rush hours or during pressures they skip hand washing and use hand sanitizers only. Most of the food handlers believed and stated that once they sanitized their hands they didn't have to wash their hands. When asked to describe when they should wash their hands at work, every participant of every group said they washed their hands after visiting rest rooms, before preparing and serving food and after coughing and sneezing. Some workers said they washed their hands when they felt that hands were visibly dirty. None of the food handlers talked about washing hands after touching their nose or scratching their body parts, before putting on gloves or when changing their gloves and after touching wiping clothes during cleaning process.

\section{Barriers to Hand Washing Practices}

The most frequent barriers to hand washing practices identified by the participants were inadequate number of hand washing stations, its accessibility, no regular supply of consumables like liquid soap, single use paper towels, broken soap dispensers and hand dryers, use hand sanitizers during rush and peak hours, laziness and forgetfulness .They also indicated that they skip hand washing during festivals times as they had to serve more customers with different food demands .Although many of the participants including their supervisors and managers were aware of relationship between unwashed hands, poor hand hygiene and its impact on food safety. Thus, managers and supervisors need to monitor the implementation of hand washing procedures in catering establishments specially during rush hours , in food preparation and service area which requires the highest level of compliance. There is no alternate to hand washing and it is one of the most effective way to prevent the spread of food borne outbreaks if followed correctly.

\section{Barriers to Gloves Usage}

When asked to describe their barriers to usage of gloves at work almost all the participants stated that it didn't fit properly in their hands and made them uncomfortable as only standard size of gloves were provided by the management. They also said that the gloves were the cause of sweating in hands and they had to change it often. Almost every participants discussed that their gloves usage was task specific and they didn't wear it continuously. The specific task discussed were handling ready to eat food items like hot and cold snack items and filling sweet boxes. They opposed the usage of gloves in food preparation area according to their opinions it slowed down their preparation processes and they preferred to use alternate methods like tongs, spatula, spoons and ladles wherever possible to avoid bare contact of hands specially ready to eat food items. On being asked about the changing frequency of gloves and washing hands during task specific activities, most of the participants stated that they changed gloves frequently and washed hands each time before and after gloving. They also discussed that mainly in two conditions they changed gloves, firstly during the change of task and secondly when it was torn due to usage. No one stated about the changing of gloves after sneezing, coughing and touching their hair and body parts.

\section{Barriers ,Opinion and perception of the participants including management regarding training and growth opportunities}

When the role of training was discussed with participants almost everybody shared their learning experiences .They also shared their positive opinions how trainings had helped them in reducing work related stress and improved their behavior and attitude towards the job. Majority of the participants were convinced regarding the benefits of trainings but they also discussed that sometimes due to work 
pressure they had to miss their training sessions and many a times their senior managers didn't allow them to attend the trainings. When it was discussed with the managers, they also didn't oppose trainings but because of the dynamic nature of catering industry they could not allow everyone to attend trainings in one single batch. They also underlined the fact that trainings not only improves the ability of the manpower but also brings a holistic improvement in an employee. They also shared that when a customer was attended by a trained employee then the probability of mistakes would be less and customer satisfaction index would be high. Reasons for variation in food safety practices among food handlers in actual work environment was also discussed with the managers and they stated that it was due to the high attrition rate of employees and at times they had to fill the vacancy in the shortest possible time period and occasionally during the festivals, they recruited semi skilled manpower for skilled positions due to the non availability of trained manpower. Most of the managers and many participants were also not aware of the FSSAI mandate of having at least one FOSTAC trained and certified food safety supervisor (FSS) for every 25 food handlers in licensed catering establishment whose responsibility would be to implement the good manufacturing and hygienic practices to ensure food safety at shop floor. Very few of the supervisors had shown their Fostac certificate proudly and had shared that during the lean periods in the catering establishment, they regularly trained their co-workers on topics like personal grooming, food safety and hygiene, customer handling ,product knowledge and time management etc. All the participants including managers in the discussion did not say anything negative about the training and they said that if the management would provide continuous training programs then it would bring a lot of positive changes in the system.

\section{Barriers in Implementing Food Safety and Standard Norms in the catering establishments.}

When participants were asked as to why they did not comply with hygienic and sanitary practices as per Food Safety \& Standard Act, 2006. Most of them stated that they were neither having complete knowledge about FSSAI norms nor they had been regularly trained on food hygiene and safety aspects by their managers and supervisors. Though they realized the importance of training in delivering safe and hygienic foods to customers but they were so busy with their daily routine jobs that they had never tried to gather relevant information. The other major barriers addressed by the food handlers and supervisors for not adopting legal framework were lacking basic understanding about new food control system, attachment with their old deep rooted practices, pressure of delivering orders on time, less space and poor infrastructure facilities. When question was asked about their awareness towards prescribed penalties and punishments for storing and preparing food under unhygienic and unsanitary conditions and serving sub standard food .Almost all the participants were showing blank faces for this statement.

\section{Discussion}

The focus groups sessions allowed the researcher to gather in depth and valuable information with regards to the perceived barriers which prevented the food handlers to comply with food safety standards in their catering establishments. The following six themes emerged from the discussion: Establishment design and facilities, Employee welfare and work place policies, Personal grooming, hygiene and sanitation, Growth opportunities, Job Pressure, Understanding of Food safety and Standard Act, 2006. Of the six themes, establishment design and facilities, personal grooming, hygiene and sanitation, trainings and understanding of Food safety and Standard Act 2006 are already identified and listed in part 2 and 
part 5 of Schedule 4 of Food Safety and Standard (licensing and Registration of Food Businesses) Regulation 2011. The document has specified requirements where compliance is essential and obligatory for food businesses and in such cases the word "shall" is used and non compliance to the required standards may lead to unsafe food handling practices and behavior and that is also linked to foodborne illnesses and outbreaks.

\section{Establishment Design and Facilities}

The defective design and layout of the premises can affect the standard of food hygiene whereas good design and layout encourages good food hygiene practices and prevent cross contamination by foodstuffs, equipment, materials, water, air supply or personnel and external sources of contamination such as pests ( Food Safety Practices, 2018). Schedule 4 of Food Safety \& Standards (Licensing \& Registration of Food Businesses) Regulation, 2011 has clearly specified the food business operators to confirm to the sanitary and hygienic requirement, food safety measures and other standards. All defined facilities to be made available to food handlers by the management . It includes availability of change rooms with lockers, toilets and hand washing stations, staff cafeteria and uniform. Therefore, the design and construction of food establishment should be appropriate for the activities for which the establishment is used.

\section{Employee Welfare and Workplace Policies}

The workplace policies is a foundation in building the culture of any organization .Catering and similar hospitality industry is focused on customer delight , therefore, to deliver safe and wholesome food to customers becomes the first priority and the legal responsibility. Every employee is expected to wear and maintain a clean uniform and follow all the do's and don't guidelines including jwellery policy, mobile usage policy, hygiene policy and health policy. According to the focus group participants "all the food safety standards were built by authorities sitting in air conditioned rooms" whereas the ground reality was different and very difficult to fulfill all the laid down food safety standards specially if workplace policies are unfavorable and not an employee friendly..Working long shifts and without weekly off can be hard on the their health. A study done by unite revealed that over two thirds of London chefs believe the long hours culture of professional kitchen is damaging their physical and mental health (Witts Sophie ,2017).Therefore, management need to revise their policies and promote good working and motivating environment. A satisfied worker can be more productive than an unsatisfied worker. Demotivating work environment leads to dysfunctional employee behavior such as absenteeism, high turnover, poor attention to quality, strikes and even sabotage ( Paul adler,1993).Food handlers also reported that they come to work during illness because of shortage of manpower. This practice should be discouraged by the catering establishment owners and managers because they are serving food to public and they should own this legal responsibility and not allow workers to work when ill .

\section{Opinions of the participants regarding Job Pressure}

Job pressure in any catering and hospitality industry is a hard core truth. The precision, accuracy, ethics , courtesy, quality, efficiency and commitment is always expected from the food handlers. They are also under lot of pressure to adhere to laid down food safety standard principles at all the points of time during work. Whereas inefficient and poor kitchen layouts with less space limit them to work as per prescribed FSSAI regulations. They also stated that such practices had affected their health , behavior ,productivity and efficiency. According to them, the restaurant kitchens are often designed in the last after all of the seating area has been designed. 
Whereas a well defined workflow in kitchen brings an exceptional customer experience (Eagle Dave,2017) without putting a toll on their health. Smooth operations and well designed kitchen creates a stress free environment where chances of cross contamination of food is low and thus, assurance to food safety .

\section{Personal Grooming, Hygiene and Sanitation}

In catering and hospitality industry good personal grooming and hygienic practices are an essential prerequisites which ensure food safety at work. Workers can carry pathogens internally and on their hands, skin and hair (Lucey John, 2006).Therefore, personal hygiene is a key element in ensuring that food is prepared safely. In relation to personal hygiene, dress code was considered as one of the most important features of food handling personnel. A well-groomed food handler projected the standard of an establishment. He/she also represented qualities of good hygiene, professionalism, style and image of an institution. During focus group discussion it was found and observed that personal hygiene of the food handler was compromised as most of them did not wear complete uniform as per the prescribed FSSAI norm. Management had not provided uniform to all the food handlers rather it was restricted to front area workers. But, it's a legislative requirement to wear neat, clean and protective clothing while handling, preparing and serving food. Therefore, uniform is to be provided to all the food handlers chefs/cooks, service staff, cashier, waiters, housekeeping staff etc including appropriate footwear, hairnets and gloves to prevent contamination of food from normal clothing. The uniform is not to be worn outside food areas and associated premises. Thus, changing facilities is to be provided by the management with lockers so that the food handlers can change clothes before starting work at their designated work stations.

\section{Hand Washing Practices}

The hands of food handlers are the principal agents in the transference of bacteria to food ( Food Safety Practices, 2018). There is no alternate to hand washing but easily overlooked way to reduce cross contamination and the transmission of food borne pathogens. One of the studies reported that 1 of every 3 cases of foodborne illnesses in restaurant industry is directly related to poor hand hygiene. Study revealed that only between 5 to $10 \%$ of those who wash their hands do it correctly. Not only it's important to wash hands properly, it was found that workers need to know when to wash their hands. It was recommended by the researcher that the food handlers to be trained on correct hand hygiene ( Hamilton Ann, 2016).Therefore, Managers and supervisors need to monitor the implementation of correct hand washing procedures specially during rush hours, in food preparation and service area which requires the highest level of compliance. Management must provide the hand washing facilities (a separate basin that is only to be used for hand washing) in kitchens with an adequate supply of hot and cold water, liquid soap, single use paper towels for drying hands and covered dustbins as per the FSSAI Schedule 4 guidelines. Besides this, all the food handlers must be trained on essential and correct steps to hand washing and when to wash hands.

\section{Gloves Usage}

Along with lack of hand washing and poor hand washing, poor hand hygiene includes bare hand contact with ready to eat food items and gloves misuse (Hamilton Ann, 2016). Hand washing is primary and gloves are secondary barrier to cross contamination. The correct use of single use disposable gloves can be an effective barrier against the transmission of germs. Disposable food service gloves are useful in the food service industry because employers can visibly monitor their workers' food safety practices, and consumers get peace of mind that there is a barrier 
between food service employees' hands and their food( Draft report, 2009). "The FDA recommends the use of barrier protection such as disposable food service gloves to stop the spread of germs in the food service industry."(Walter Brown,2017) .The use of gloves and maintaining a proactive standard practice in all food handling areas is important. Gloves to be used as preventive measure rather an eye wash in front of customers.

\section{Growth Opportunities}

Every human on this earth has a desire to grow in their career. It has got a huge impact on their happiness and if employee is not satisfied with their growth and development opportunities in their existing organization then they would not involve themselves into continual improvement projects and in the end they would leave the job , if frustration level goes high. Therefore, the key to motivate any employee in an organization is to give them the opportunities for internal growth and promotions even if they're small. This way employees would feel motivated and on seeing development opportunities within the organization, they would prefer to continue with their jobs and this in turn would increase employee engagement and decrease variation in food safety practices among food handlers. An employee's perception of internal growth and development opportunities is one of the more important predictors of employee engagement. In a study, when employees were asked to rate their agreement with the following statement: "This company provides attractive opportunities for growth and development," only $61 \%$ of employee responses in 2017 were favorable and rest of the responses were unfavorable and is one of the lowest measured score on this question to date (Rogel Charles, 2018).

\section{Understanding of Food Safety and Standard Norms}

It is vital for all the food handlers to follow and understand basic food safety and standard practices .Unless employees understand and follow basic food protection principles, they may unintentionally contaminate food packaging, water and other workers, thereby creating the opportunity to transmit foodborne illness ( Lucey John, 2006). Ignorance is no excuse specially when one is serving food to public.. Also, as per schedule 4 of FSS Act , all the Food Business shall ensure that their technical managers and supervisors possess appropriate qualifications, knowledge and skills on food hygiene principles and be able to monitor and supervise food safety and quality of the products being processed, stored and served, identify food hazards, take appropriate preventive and corrective actions. One of the studies had found that lack of knowledgeable managers present during all hours of operations is a cause of food borne illness in catering establishment whereas same study also revealed that knowledgeable and certified food safety managers knows and follow safe food handling procedures and encourages other workers to do so ( Hamilton Ann, 2016). Employers have a legal responsibility to provide and arrange FoSTaC ( Food Safety Training and Certification) food safety supervisor trainings for their employees as per Section 16(3)h of FSSA Act 2006. So that all food handlers would be aware of their roles and responsibilities in protecting food from contamination. Proper hygiene practices should be communicated prior to employment and reaffirmed with periodic training programs (Lucey John, 2006). These training will have positive impact on the organization's growth in both qualitative as well as quantitative way.

\section{CONCLUSION}

Findings of the FGD indicated that the regular food safety training programs to be organized by the management for the managers as well as for the food 
handlers. The trained Food Safety Supervisor would further train the food handlers down the line in continuous basis so as promote safe food handling practices. The catering establishment owners themselves also need to participate in refresher training programs and conferences organized by FSSAI. This would help them in gaining better insight about the FSSAI regulations and day to day revisions made in the regulations. All the other emerged themes mentioned in the affinity diagram to be addressed effectively specially related to layout, infrastructure facilities and employee welfare and job policies. The management and the managers should strive to promote food safety culture at work place where everyone should be responsible for the implementation of food laws and regulations. . Further research is required to determine whether the barriers and opinions identified by participants are representative of a larger population of catering establishments. The perceived barriers gathered from these focus groups sessions can provide a basis for the development of resources for the stakeholders/policymakers and to sensitize the catering establishment administrators/owners and workers towards the specific food safety needs .

\section{Abbreviations}

FSSAI:

Food Safety and Standard Authority of India

FSS:

\section{Food Safety Supervisor}

FOSTAC:

Food Safety Training and Certification

FGD:

Focus Group Discussion

FBO:

Food Business Operator.

IDSP:

Integrated Disease Surveillance Programme

ADD:

Acute Diarrhoeal Disease

\section{REFERENCES}

1. Adams M, Motarjemi Y.1999.Basic Food Safety for Health Workers.WHO Geneva. Retrieved from

http://citeseerx.ist.psu.edu/viewdoc/download?d oi=10.1.1.385.1166\&rep=rep1\&type=pdf. $\quad$ Last reviewed on 25th Nov 2018.

2. Anon, 2011. Food hygiene regulations. Official Journal of the Republic of Turkey . Retrieved from

https:/www.intechopen.com/books/significance -prevention-and-control-of-food-related-

diseases/food-safety-problems-and-solutions Last reviewed on 25th Nov 2018

3. Codex Alimentarius. 2009. Food Hygiene. Codex Alimentarius Commission, Joint FAO/WHO Food Standards Programme, Rome. Retrieved from

https:/www.intechopen.com/books/significance -prevention-and-control-of-food-related-

diseases/food-safety-problems-and-solutions Last reviewed on 25th Nov 2018

4. Cogan T. A., J. Slader, S.F. BloomWeld and T.J. Humphrey. 2002. Achieving hygiene in domestic kitchen: The effectiveness of commonly used cleaning procedures. Jour- nal of Applied Microbiology. 92: 885-892. Retrieved from

https://www.intechopen.com/books/significance -prevention-and-control-of-food-related-

diseases/food-safety-problems-and-solutions . Last reviewed on 25th Nov 2018

5. Collins, J. E. 2001. Impact of changing consumer lifestyles on the emergence/re-emer- gence of foodborne pathogens. Emerging Infectious Diseases. 3(4): 1-13. Retrieved from https://www.intechopen.com/books/significance -prevention-and-control-of-food-relateddiseases/food-safety-problems-and-solutions Last reviewed on 25th Nov 2018. 
6. Draft Report, 2009. Barriers to Bare Hand Contact.

Retrieved

from

http://www.foodprotect.org/media/reportdate/809\%20Food\%20Contact\%20Utensil\%20and\%20

Barrier\%20Usage\%20Draft\%20Booklet.pdf. Last reviewed on 26th Nov 2016.

7. Dudovskiy John.2018.Snowball Sampling. Retrieved from https://researchmethodology.net/sampling-in-primary-datacollection/snowball-sampling/. Last reviewed on 25th Nov 2018.

8. Eagle Dave,2017. How to Build Your Restaurant Workflow for Success with Your Point of Sale. Retrieved from https://www.kounta.com/restaurant-kitchenworkflow/. Last reviewed on 25th Nov 2018.

9. Food Safety and standard Act 2006 , Rules 2011. International Law Book Company , 7th Edition . 2012

10. Food Safety Practices. 2018. Retrieved from https://assets.publishing.service.gov.uk/governm ent/uploads/system/uploads/attachment_data/fil e/757108/201810241-20_04_05_JSP_456_DCM_Pt_2_Vol_3__Ch_3_Food_Safety_Practices_Amnd_012.pdf. Last reviewed on 25th Nov 2018.

11. FSSAI, 2017. Guidance Document : Food Safety and Management System. Food Industry guide to Implement GMP/GHP Requirement. Catering Sector .Edition First. Online available at www.fssai.gov.in. Last reviewed on 25th Nov 2018.

12. FSS Regulation 2011.Retrieved from https://www.fssai.gov.in/home/safe-foodpractices/FOOD-SAFETY-AND-HYGIENEREQUIREMENTS.html. Last reviewed on 25th Nov 2018.

13. Hamilton Ann, 2016. Study : Three main causes of food borne illness in eateries. Retrieved from http://www.fosters.com/article/20160406/NEWS /160409608. Last reviewed on 26th Nov 2018.
14. Julie,Raj.2012.Food Culture of Delhi from https://dastaanjmc.wordpress.com/knowtheunk nown/food-culture-of-delhi/).Last reviewed on 25th Nov 2018.

15. Krueger RA \& Casey MA.2000 Focus Groups: A Practical Guide for Applied Research, 3rd ed. Thousand Oaks, CA: Sage Publications.

16. Lucey John , 2006. \{ersonal Hygiene and food safety tips. Retrieved from https://www.foodqualityandsafety.com/article/p ersonal-hygiene-and-food-safety/.Last reviewed on 26th Nov 2018.

17. McLeod, S. A. 2017. Qualitative vs. quantitative research. Retrieved from https://www.simplypsychology.org/qualitativequantitative.html. Last reviewed on 25th Nov 2018.

18. Paul Adler, 1993. Time and Motion Regained. Retrieved from . https://hbr.org/1993/01/timeand-motion-regained . Last reviewed on 25th Nov 2018.

19. Rogel Charles, 2018.Growth and Development and Employee Engagement. Retrieved from https://www.decision-wise.com/growth-anddevelopment-opportunities-and-employeeengagement/. Last reviewed on 28th Nov 2018.

20. Sauro Jeff, 2016. How and when to use an affinity diagram. Retrieved from https://measuringu.com/affinity-diagram_old/. Last reviewed on 26th Nov 2018.

21. Sharma Charu.2017. Food and Beverages. How Restaurant Industry is Growing up with Trend.Retrieved from https://www.franchiseindia.com/restaurant/Ho $\mathrm{w}$-Restaurant-Industry-is-G.Last reviewed on 25th Nov 2018

22. Sudershan R.V., Kumar R.N., Polasa K.2012 "Foodborne diseases in India-a review," British Food Journal, vol. 114, no. 5, pp. 661-680, View at Publisher - View at Google Scholar ·

23. Sushma Meenakshi, 2018.India's Top Colleges not following food safety standards: FSSAI 
Report. $\quad$ Retrieved from

http://www.downtoearth.org.in/news/india-s-

top-colleges-not-following-food-safety-

standards-fssai-report-59755). Last reviewed on

25th Nov 2018.

24. Walter Brown,2017. The right gloves for the job.Part III Food Service. Retrieved from. https://blog.ammex.com/the-right-gloves-forthe-job-part-iii-food-service/\#.W_r65-JX7IU. Last Reviewed on 25th Nov 2018.

25. Witts Sophie ,2017.Majority of London Chefs Struggle with Long working hours. Retrieved from

https://www.bighospitality.co.uk/Article/2017/0 4/27/Majority-of-London-chefs-struggle-withlong-working-hours?. Last reviewed on 25th Nov 2018.

26. Temelli, S. and C.M.K. Şen. ve Anar, Ş. 2007. Determination of Hygiene Status of Meat Seperation and Cheese Production Workers' Hands (in Turkish). The Journal of the Faculty of Veterinary Medicine, Kafkas University.24 (1-2-3-4): $\quad$ 75-80. Retrieved from https://www.intechopen.com/books/significance -prevention-and-control-of-food-relateddiseases/food-safety-problems-and-solutions . Last reviewed on 25th Nov 2018

27. Yiğit, V. \& Duran, T. 1997. Institutional Nutrition Technology I (in Turkish). Ekin Publishing, Istanbul, Turkey. Retrieved from https://www.intechopen.com/books/significance -prevention-and-control-of-food-relateddiseases/food-safety-problems-and-solutions . Last reviewed on 25th Nov 2018

28. Yasmeen Afshan,2018.Food Poisoning,a common outbreak in 2017. Retrieved from https://www.thehindu.com/news/national/foodpoisoning-a-common-outbreak-in2017/article22392234.ece. Last reviewed on 25th Nov 2018. 